\title{
Indigeneity and Indigenous Agency in Latin America
}

\author{
Adrián D. Cetina Catzín \\ Florida International University
}

Despite the advances and changes experienced in the field of indigenous studies, the approach to indigenous agency in the arenas of the globalized world has resulted in narratives that frequently reduce them to roles of vulnerability, assimilation and resistance. However, these approaches overshadow the complex and diverse relationships that indigenous groups have with the structures of the globalized world. Within the framework of these considerations, this paper analyzes the implications derived from the background approach to the agency of indigenous groups, and the reductionism resulting from attempts to disarticulate the negative judgments to which indigeneity has been linked. Likewise, it analyzes and discusses the contributions of post-colonialism and decoloniality to contemporary perspectives in the field of indigenous studies, the changes and challenges derived from the self-awareness developed on the epistemological and political challenges inherited from the dichotomous visions that directed the historical and anthropological canons, as well as their paradoxical contributions to the reduction of indigenous agency.

Keywords: indigeneity, otherness, agency, ethnogenesis, ethno-exodus

\section{INTRODUCTION}

In the field of indigenous studies, scholarly debates have closely analyzed the effects resulting from encounters between indigenous groups and the many diverse forces of globalization (e.g. Bessire, 2014; Cepek, 2018). From these encounters have developed top-down narratives describing both negative and positive outcomes, which reduce the agency of indigenous groups, and pay little attention to the meaning that the structures of globalization hold for them, or how these groups contribute to outcomes through their interaction with those structures (Hutchins and Wilson, 2010; Hipwell, 2007). In part this was because the echoes of dichotomous views, which characterized early anthropological work on non-Western cultures, remained strong until the last decades of the twentieth century (Peirano, 1998). But the contributions made by Geertz (1974), Fahim (1980), Rabinow (1985), Trouillot (1995; 2003) -among others- eventually led to the re-evaluation of the anthropological paradigm of otherness, the emergence of native anthropologists, and the growing concern for the silences derived from the discursive construction of otherness (Peirano, 1998).

These changes were reflected in the anthropological work and its interest in becoming a vehicle for communicating the point of view of the "Other"; a voice for self-representation. Although the discussions generated from these changes paid off by opening space for silenced voices, the academic approach to indigenous issues in Latin America has often reduced the agency of indigenous groups to a role of victimization; passive and vulnerable subjects to the challenges and pressures of the global world (Warren, 
2003). While these early approaches provide valuable insights into the relationships between indigenous groups and structures of globalization, they also draw attention away from these groups as important shapers of the processes that maintain their functioning.

In contrast, works such as those by Cepek (2018) and De la Cadena (2015) offer examples of how indigenous groups continually negotiate with structures of globalization by transiting between "indigenous" and "non-indigenous" spaces to survive within global tourism and oil markets; they describe the diverse, and complex, relationships that indigenous groups establish with these industries beyond the negative impacts with which they are commonly associated. These narratives challenge perspectives that neglect the agency of native people and offer a less polarized gaze that does not reject the intergenerational transformations that unfold as indigenous groups transition from oral tradition to internet use (Beyette and LeCount, 2017: p. xiii).

Within the framework of these considerations, this paper analyzes the implications derived from the background approach to the agency of indigenous groups, and the reductionism resulting from attempts to disarticulate the negative judgments to which indigeneity has been linked. We first discuss the background behind the dichotomous visions of otherness and their repercussions on the conceptualization of agency in non-Western cultures. Next, the contributions of post-colonialism and decoloniality to contemporary perspectives in indigenous studies are analyzed. Next, the changes and challenges derived from the selfawareness developed on the epistemological and political challenges inherited from the dichotomous visions that directed historical and anthropological canons, as well as their meanings for the conceptualization of indigeneity and indigenous agency, are examined. Finally, the final reflections of the work are presented.

\section{OTHERNESS AND THE CONCEPTUALIZATION OF AGENCY}

In 1978 Said published "Orientalism", a book that analyzed the power of biased views present in most anthropological and historical narratives about the "East". For Said these perspectives founded mistaken, stereotyped and exotic cultural representations of the "East"; it was a politicized vision of reality whose structure promoted the difference between the familiar (Europe, the West, "us") and the strange (the East, the Orient, "them") (Said, 1995:43). In relation to this, post-colonialist critiques by authors such as Said (1995), Fabian (2014), Thomas (1994), De Certeau (1997), and Spivak (1998; 2014) showed the limits that such a distinction set on thinking; how it limited what Western scholars could experience or say about "Other" Cultures.

These critics argued that this fragmentation had implications beyond merely operating as "a strategy that mobilized social and cultural difference" (Gupta, 1997: p.243), but was instead at the core of the entire genesis of named ethnic groups under the shelter of stereotypical labels that promote homogeneity (Restall, 2004). More specifically, this has been characterized in the field of social science as ethnogenesis, which refers to the historical process by which non-Western ethnic identities have been constructed from a Western perspective. Restall (2004), Gabbert (2004) and Castañeda (2004) problematize these identity constructions by arguing that they are based on monolithic categories that homogenize ethnic identity, making specific groups of the indigenous population visible while others are erased from the scene, which restricts their capacity to act and exist outside of them; that is, they also restrict their agency.

Thus, the labels associated with ethnic groups through the processes of ethnogenesis exemplify the most evident consequences of otherness, they refer to the existing interactions between discourses and power relations from which ethnicity is fabricated as a political tool (Roosens, 1989; Vargas Cetina, 2013). In this regard, Hill (1996) highlights that ethnogenesis synthesizes political and cultural struggles to exist, as well as the historical consciousness about these (Hill, 1996, p.2); a sophisticated encryption that evades epistemological questioning of how discursive foundations constrain indigenous people's actions, or understandings of indigenous ethnic identity. The above is related to Said's (1995) discussion of the cultural essentialization of the "Orient", concluding that an important characteristic of essentialism is that it is encrypted in the consciousness of the "Other". 
According to Paradies (2006), essentialism represents the politics of differentiation and materializes them through the imprisonment of individuality in pre-established monolithic categories of existence, such as indigenous and non-indigenous. Likewise, Paradies (2006) points out that essentialism presents particular challenges to the status quo of indigenous groups insofar as it denies the changes and transformations of indigenous cultures outside the parameters of their idealized identity (Paradies, 2006: p.361). Kosko (2013) adds that indigenous groups not only experience a lack of power to change the processes that affect them, but also a vulnerability of their agency by not being able to act outside the categories that regulate their genesis and their right to "self-representation"; especially in Latin America. In this context, the idea of indigeneity emerges as a product of the politics of differentiation of otherness, which continues to encapsulate many of the negative connotations with which it was initially endowed, despite the progress made in recent decades with respect to the conceptualization of "indigenousness".

Indeed, otherness is usually related to practices of differentiation and objectification rooted in politics of domination and superiority that govern the "Other", the inferior (Said, 1995; Fabian, 2014). However, Fabian (2014) explains that otherness is more related to self-identification than to the empirical reality of the "Other", by arguing that for political and historical reasons otherness is necessary to establish and understand self-identity, for there to be an "us" there must be a "them" (Fabian, 2014: p.181). Fabian's analysis highlights the complexity in which otherness operates: on the one hand, there is a growing interest in deconstructing it as a result of post-colonial critiques that evidenced the normalization of differentiation practices; but, on the other hand, otherness is a necessary juxtaposition for self-identification. According to Gupta (1997), identity and otherness are produced simultaneously with the establishment of the "local" and the "community" (Gupta, 1997: p.13); that is, "we" are also the "Other", and the "Other" is part of us.

In a similar way, Fassin (2001) points out that there is a close relationship between otherness and identity politics; however, his perspective analyzes this link beyond power relations. Thus, Fassin suggests that otherness represents a political tool that not only controls one's visions of the "Other" but also inscribes their bodies. Although various disciplines have identified these implications adjacent to otherness, in anthropology and cultural studies the emphasis has been on inequalities, exoticism, and marginalization, thus ignoring the connection between otherness and the agency of the cultures under study. However, sociological theory has paid more attention to the subject, authors such as Foucault and Bourdieu locate this connection by pointing out the complex relationships established between discourses, social structures and the individual.

On one hand, Foucault's (1990) analysis of "The History of Sexuality" describes how the interests of the bourgeois class founded a discourse that controlled and confined sexuality during the eighteenth century. Foucault used this example to expose the repressive hypothesis, or how control over the discourse of sex limited the way people talked about sex, repressing their sexual impulses; (Foucault, 1990). Although at first glance it may not be easy to appreciate the contributions of such ideas to the study of indigeneity, because Foucault's work was not conceived as a critique of the post-colonial condition, if we take into account that the theoretical core of indigeneity is largely focused on the effects that hegemonic discourses have on the production of knowledge and the representation of the "Other." then it is possible to draw a parallel with Foucault's initial arguments, as he suggests that the influences of such discourses go beyond the discursive dimension and have direct effects on individuals, being able to direct and/or restrict their actions.

Similarly, Bourdieu (1997) places the problem in his analysis of habitus in which he points out that our actions are influenced by norms and other social structures (Csordas, 1990); therefore, for Bourdieu, habitus represents the universal mediation that originates the individual's practices (Bourdieu, 1977: p.79). However, Bourdieu points out a dimension of habitus that remains obscured due to the fact that habitus is not only a limiting structure that organizes practices and their perception, but also a structured structure (Bourdieu, 2013: p.170). In other words, habitus and structures are closely related, so that while social structures restrict habitus, habitus also affects and reinforces social structures. Although Bourdieu's habitus is not an equivalent of the individual's agency, it helps to locate how the power of hegemonic discourses embedded in the social structure is constantly created and reinforced through the interaction of the individual and the structure; this serves as an argument to revisit the proposal of agency as a counterweight 
to hegemonic discourses (see Scott, 1990), but without losing sight of the symbiotic relationship that exists between individual and structure.

This relationship has been repeatedly pointed out within sociological theory, in this field, agency and structure are considered as poles that connect a continuum; however, it has also been pointed out that the study of agency can be misleading and ambiguous because it is often examined in opposition to structure (e.g. Sewell, 1992; Hays, 1994; Meyer and Jepperson, 2000; Fuchs, 2001; Shapiro, 2005). The above points are relevant for cultural studies on indigenous groups in Latin America because their agency is often understood from a polarized framework interested in the resulting conditions of otherness and subjugation, while the bilateral relationship between agency and structure is ignored.

The light that post-colonial theory put on otherness and essentialism originated a multidisciplinary interest in reversing the silences and oppression produced by Western methods of knowledge production. As a result, much Western epistemological work has focused on disarticulating the essentialist categories with which indigenous groups have been associated, neglecting the implications for their agency and their ability to exist outside of those parameters established from Western optics (e.g. Nash et al., 2013; Beyette and LeCount, 2017). In this regard, Montejo (2002) and Castañeda (2004) point out that the intellectual promise of disarticulating essentialism and understanding non-Western cultures critically has not been fulfilled, however, attempts to do so produced an inverted narrative founded on the same principles that attempts to deconstruct.

\section{POST-COLONIALISM, DECOLONIALITY, AND THE CONCEPTUALIZATION OF INDIGENEITY}

Post-colonialist analysis of anthropology's contributions to the objectification of cultures highlighted the political implications and dominant narratives perpetuated in the process of knowledge production (Said, 1995; Trouillot, 1995). The above derived in a self-awareness that expanded beyond the field of anthropology bringing light to the silences, gaps, and conditions of marginalization experienced by minority groups as a result of the prevalence of patterns of colonial dispossession and violence crystallized in more sophisticated control mechanisms that transmit the echoes of dominant discourses to the most intimate spaces of the lives of those groups (Cepek, 2018; Gregory, 2004; Robbins, 2012). In this regard, the importance of illuminating these "new" forms of colonialism to understand how they operate unnoticed has been highlighted (Mitchell, 1991; Gregory, 2004).

Such pronouncements have been at the heart of neocolonialism and decoloniality, as well as their commitment to analyze and disarticulate existing inequalities in the global system. For example, Tuck and Yang (2012) posit decolonization as a means to repatriate land and life to the "Other," and reverse the Westernized structuring of the world. While their intentions are good, their proposal falls back on a utopian vision of operationalizing decolonization where "indigenous" and "non-indigenous" worlds remain isolated from each other, and where Westerners would be willing to relinquish their power. These types of interpretations of post-colonialism and decoloniality exemplify Ribiero's (2011) concerns regarding radical interpretations of these theories, as for him this overemphasis on colonialism and coloniality can, ironically, (re)generate that which needs to be analyzed and overcome (Ribeiro, 2011: p.290)

In this sense, the exaggeration of the precepts that guide post-colonial and decolonial theory led to an inverted polarization based on the very principles it seeks to deconstruct. It is a posture of analysis where the colonial and non-colonial dichotomy remain separate in a critique that now casts coloniality as a necessary juxtaposition to explain decoloniality. This polarization revives early ideas about decolonization and anti-coloniality that were supported by a vision of "natural opposition", which was conceived as the meeting of two forces distanced by the memory of the violence that marked their first encounter (Fanon, 2007 [1963]: p.36)

Although history provides evidence to support the background described by Fanon about the relationship between colonizers and colonized, focusing too much on the historical past of colonialism and taking a drastic stance on it clouds the nature of its contemporary relations. However, this does not mean closing one's eyes to the pain and suffering produced by colonialism, but rather acknowledging the past 
without condemning it in order to reconcile the two worlds. Otherwise, continuing to condemn the colonial past denies the support and contributions of the "colonizers" committed to changing the paradigm of otherness, and instead perpetuates its principles in a reverse narrative posed from the voice of the "Other" for the "Others"

Despite the setbacks that post-colonialism and decoloniality have suffered, the changes they brought about contributed to a re-evaluation of indigeneity. From this, two main perspectives have developed with respect to indigeneity as part of the global context. Of these, the first views indigenous groups as survivors of the past in the present, passive and vulnerable to processes of extinction and/or complete assimilation; the second describes a picture of ongoing resistance to global forces, activism, and negotiations for the right to autonomy and self-determination (Warren and Jackson, 2003; Wilson and Steward, 2008). Although both analytical positions illuminate some of the challenges surrounding indigenous groups, the rigid categories that support their analysis reduce indigenous agency to a desire to resist and seek to reverse the pressures and inequalities of global forces (Castañeda, 2004)

On this subject, De la Cadena and Starn (2007) explain that despite the changes produced by the indigenous movements at the end of the 20th century, the habit of describing indigenous groups as autochthonous or pre-modern remains, which continues to mark their experiences as actors alien to the contemporary world (De la Cadena and Starn, 2007: p.9). Similarly, they argue that being indigenous today involves diverse experiences rooted in political conflicts, and that it is not an inert state of being (De la Cadena and Starn, 2007: p.11). That is, although the conceptualization of indigeneity has gone through a process of transformation, and the monolithic idealization of indigeneity has been attenuated, the social and political movements in favor of it have not been fruitful in separating the dichotomies of otherness.

Even though the De la Cadena work discusses important issues regarding indigeneity, its approach is problematic because while it identifies the political conflicts and diverse relationships that indigenous groups sustain with the Western world, it also reflects dichotomous distinctions that separate the two worlds (Erazo and Jarret, 2018: p.149). For Erazo and Jarret, the analyses that rely on dichotomous views offer a limited view of the changes experienced by indigenous groups, in contrast, approaches that consider multiple forms of power and knowledge provide a more comprehensive perspective of contemporary indigenous reality (Erazo and Jarret, 2018: p.159). Similarly, native scholars such as Macas (2003) and Hunt (2014) have noted the importance of developing such an approach; for example, Macas (2003) argues that an approach open to possibilities beyond dichotomy would allow indigenous groups to gain control over processes of ethnogenesis, such that they could combine and recombine "indigenous" and "nonindigenous" knowledge to redefine their contemporary identity beyond the hegemonic narratives that tie them to a distant past (Macas et al., 2003: p.219). In other words, it would allow indigenous groups to question the epistemological and ontological foundations that link their genesis to facts and fictions responsible for fading some indigenous people from current public view.

In this sense, in order to dissociate indigeneity from otherness, it is necessary to begin by ceasing to polarize the analysis of the encounters that exist between the "indigenous" and "non-indigenous" worlds in order to visualize the complexities in which their diverse relations of coexistence develop. Otherwise, as long as the principles guiding the analysis of indigeneity are based on a dichotomous ontology, indigeneity will continue to be a figure of otherness that projects stereotypical visions of indigenous groups and restricts their agency as actors in the global world.

\section{MULTICULTURALISM, CULTURAL POLICIES AND INDIGENEITY IN LATIN AMERICA}

The contemporary meanings and experiences of indigeneity are complex, involving political conflicts that deserve a more detailed examination in order to understand the issues that circumscribe contemporary indigenous identity and agency (De la Cadena and Starn, 2007). It is necessary to recognize the political and discursive uncertainty on which indigeneity rests, although the changes achieved by the indigenous movements of the late twentieth century have been described as progressive, they have also been criticized for the new dilemmas and issues that these changes have brought (Hale, 2004; De la Cadena and Starn, 2007). Although indigenous movements managed to capture international attention and gain recognition 
for marginalized minorities (Niezen, 2000; Hale, 2004), they only directed the spotlight on specific groups. While Hooker (2005) points out that such attention and recognition excluded Afro-Latino minorities even though they have also experienced a long history of marginalization, Hale (2004) criticizes the political foundations underpinning the recognition of indigenous rights and self-determination.

For Hale (2004) the transition towards multiculturalism and indigenous rights represents a cultural project of neoliberalism, because although the change contributed to the enhancement of indigenous voices during the process, the limits of their transformative aspirations were also adjusted (Hale, 2004: p.17). On the above, Hale (2004) adds that the result was a framework of indigeneity based on the model of the "permitted Indian", which according to him consists of a contradictory configuration where the demands for reforms and indigenous rights are developed within predetermined limits, since these concessions cannot transgress non-indigenous rights or allow indigenous people to accumulate the necessary power to change the system.

Similarly, Jackson (2009) and Rappaport (2005) point out the political dimensions and the heterogeneity intrinsic to indigenous movements by exposing the diverse contexts in which they have developed. Both works illuminate the tension between the state and the uprising of movements that evidence the discursive dimension on which part of the transformations rest. Similarly, Postero (2007) identifies this fragile relationship in his critique of the obstacles faced by cultural policies of recognition, for while "traditional indigenous" lifestyles are constitutionally recognized, in practice this recognition is absorbed by the economic realities of rapid urbanization or resource exploitation (Postero, 2007: p.8). This discursive crossroads represents what Blaser (2014) considers the ontological premise of indigeneity, being that in order to address the precepts that circumscribe indigeneity it is necessary to consider that these are connected to other systems of meanings, and their disarticulation requires attending to such connection (Blaser, 2014: p.6).

For their part, native scholars such as Smith (2013) and Hunt (2014) have highlighted the importance of establishing a dialogue that recognizes the connection between "western" and "non-western" ontologies in order to produce a stable reorganization of the different layers that shape the unstable understanding of indigeneity. Likewise, Hunt (2014) argues that this conversation must occur in the spheres of mainstream academic debates rather than occurring on the periphery, thereby resonating with the efforts of indigenous movements. LaRocque (2011) reinforces this idea by suggesting that in peripheral spaces Native authors will continue to be discredited by non-native scholars. Otherwise, attempts to re-conceptualize indigeneity as an isolated category of otherness will continue to add new levels of complexity to the political struggles of indigenous identity.

Although changes have been achieved, new challenges have also been established to dissociate the negative relationship between "indigenous" and "non-indigenous". In fact, one of the main paradoxes resulting from indigenous movements is the contradiction between the recognition of indigenous rights and indigenous self-determination. In the first instance, this paradox refers to the predetermined limits described by Hale (2004), since the recognition of these rights occurs within the terms established by non-indigenous people. Furthermore, there is the fact that the forces that legitimize indigenous rights are those that indigenous movements seek to counteract, which reaffirms indigeneity as a subjugated domain of the nonindigenous, since access to indigenous rights is conditional on self-identification as indigenous; in other words, their acceptance involves internalizing otherness.

But beyond the political negotiations inherent in the demand for and provision of indigenous rights, the exercise of those rights involves the adoption of discursive narratives about indigeneity that distort senses of "indigenous" belonging and identification. These relationships resonate with what Spivak (1988) describes about the position of the subaltern in the articulation of meanings, he argues that, in the end, things involving the subaltern, the third world and the other, are tainted with western political and economic interests. Perhaps, contemporary perspectives on this work will question Spivak's analysis because of the time that has passed since it was first published and the relations between subaltern and Western have changed. However, the fact that these changes are legitimized on the hegemonic narrative that was used to explain subaltern life, culture and history perpetuate a dichotomous loop in which subalterns are secondary 
actors in their own lives, where much is known, and little is questioned, about the ethnogenesis of indigenous groups.

For example, the proposal of indigenous self-determination exemplifies how the western narrative on indigenous cultures is fundamental to the exercise of this right, because beyond the political domain intrinsic to the demand for this right and its legitimization, exercising it starts from the adoption of the label "indigenous", as well as self-identification with a specific ethnic group. This evokes and revives the epistemological and ontological foundations of the narratives of early linguistic, anthropological and historical works that were responsible for categorizing the "Other" under different ethnic labels. Thus, the incorporation of these categories into subaltern self-determination processes implies, to some extent, the adoption of Western political and economic interests. Moreover, embracing these narratives legitimizes the gaps, silenced histories and hegemonic perspectives from which the lives of subalterns have been narrated (Trouillot, 1995; Palmié, 2013), from which facts and fictions have become part of their history and/or their history itself, that is, their genesis (Pred, 2004). In this context, Hale (2004) argues that in order to change this paradigm, "indigenous groups" must enter the domain of Western power to challenge the "indigenous" / "non-indigenous" dichotomy, and redefine the terms of indigenous struggle (Hale, 2004: pp.19-20). However, this does not necessarily mean that the concepts themselves should be erased, but rather to question the obvious, to know the intersectionality of ethnic identity as a tool for self-identification and resistance, and its role as a construction of power that justifies and reproduces existing hierarchies (Martínez Novo, 2006).

In the case of Latin America, Hale (2006), Martínez Novo (2006) and Postero (2007) problematize the political and discursive ambiguity surrounding constitutional reforms that recognize indigenous groups, and multiculturalism in Latin American countries (Guatemala, Mexico and Bolivia). According to Hale and Martínez Novo, the emergence of multiculturalism, paradoxically, has made racial hierarchy more resistant (Hale, 2006: p.210), resulting in the construction of an empty ethnic identity (Martínez Novo, 2006: p.86). Martínez Novo points out that the lack of clarity in the approach to multiculturalism and indigenism in Mexico has led to inconsistency in the country's cultural policies because while the multicultural composition is recognized, "indigenous rights" are granted to the country's different ethnic groups, and federal funds are allocated for indigenous programs, although there are no clear guidelines, at least in practice, to regulate who can declare themselves as "indigenous" in order to access these supports. Similarly, little has been done to promote indigenous rights and other benefits that indigenous movements achieved beyond constitutional agreements, not to mention that the understanding of indigeneity is ambiguous and often leads indigenous groups to establish different types of identity negotiations to navigate the nation's cultural policies and programs. This evidences the connection between the discursive and political dimensions of indigeneity, as well as the ambiguous and paradoxical foundations that perpetuate the dichotomous loop that keeps indigeneity as a subjugated category of western thought.

\section{CONCLUSIONS}

Said (1995) highlighted the negative implications of the politics of differentiation, explaining that the western fascination with the exotic produced stereotypical views of non-western cultures. But beyond the essentialisms created, otherness has also contributed to restricting the agency of indigenous groups by portraying them as inert actors and outsiders to the "western world". Even after the contributions made by scholars such as Geertz (1974), Fahim (1980), Rabinow (1985) and Trouillot (1995; 2003), indigenous agency, especially in Latin America, has often been reduced to roles of passive victimization vulnerable to the challenges and pressures of the global world (Warren, 2003).

Although postcolonial and decolonial critiques (e.g., Said, 1995; Fabian, 2014; Thomas, 1994; De Certeau, 1997; and Spivak, 1998; 2014) showed how dichotomous views distinguishing between Western

and non-Western restricted what Western scholars could experience or say about "other" cultures. This fragmentation not only operated as a strategy that mobilized social and cultural difference (Gupta, 1997: p.243), but has been at the core for the entire genesis of ethnic groups baptized under the broad umbrella of racialized labels that promote their unity and homogeneity (Castañeda, 2004). While the repercussions that 
these visions have had on the marginalization of the "Others" have been pointed out, to a lesser extent the repercussions on their agency have been addressed.

In part, post-colonial and decolonial critiques helped to denounce the pressure and inequalities experienced by indigenous groups; however, the emphasis placed on the principles of these theories produced rigid categories of opposition that were used as foundations to disarticulate the indigenous and non-indigenous dichotomy. This is problematic because as long as the principles guiding the analysis of indigeneity remain operationalized from a dichotomous vision, indigenous peoples will continue to be figures of "otherness" and their agency will remain restricted. The adoption of a dichotomous ontology rejects the relationships that currently exist between "western" and "non-western" cultures. The need for perspectives that recognize how diverse and complex these relationships are has been pointed out by both native and western scholars (see Balser, 2014; Hunt 2014; Hunt 2014; Jackson, 2009; LaRoque, 2011; Postero, 2007; Rappaport, 2005; and Smith, 2013), who have emphasized the need to establish a dialogue that admits the connections between various ontologies in order to disarticulate the fixed essentialism that restricts indigenous agency and governs its genesis.

As academics, anthropologists, sociologists, ethnographers, etc. we experience others as our interlocutors; however, experiencing them as outsiders is not a logical, psychological, and certainly not a political requirement (Fabian, 2014: p.178). Up to this point I was cautious not to reveal my position as a non-western scholar, because part of my goal was to establish a dialogue within the academic debates without appealing to any special treatment for being a member of an indigenous community, and thereby avoid reinforcing the dichotomies I have discussed here. Rather, my intention has been to achieve a dialogue in which I was not experienced as the "Other"; which I hope I have achieved. Perhaps there are those who will question the objectivity of what I have presented here by contrasting my positionality as a contemporary Maya with the fact that I am being taught by "western" academics, however, rather than clouding my judgment with their teachings, what it has done is to dispel the doubts I had about my ethnic identity; although I grew up learning about the "Maya", I learned little about myself as a contemporary Maya.

From the framework of the ethnoexodus proposed by Castillo et al. (2017), which proposes the elimination of oneself from an identity construction in order to assume other identity(ies), I separated myself from the limitations of the construction of my ethnic identity to transcend the borders that imprison indigeneity in order to establish a dialogue between coevals in which the gaps that insist on dividing our world(s) are blurred. Although dichotomies such as the one represented by the notions of indigenous and non-indigenous are part of the system that organizes our worldviews, the approach from optics that transcend these dichotomies can allow indigenous peoples to take control of the process of ethnogenesis, to question the epistemology and ontology that links their genesis with specific facts and fictions (Macas, 2003). As Martínez Novo (2006) suggests, in the first instance it is a matter of recognizing the intersectionality of ethnic identity as a tool for self-identification and resistance, and its role as a construction of power that justifies and reproduces existing hierarchies. Then, as with Foucault's repressive hypothesis, to gradually disarticulate the limitations constructed around non-Western ethnic identities and thus begin to reconceptualize them.

\section{ACKNOWLEDGEMENTS}

This paper and the research behind it would not have been possible without the financial support of the Science and Technology Council of Mexico (Consejo Nacional de Ciencia y Tecnología, CONACYT).

Many thanks to Dr. Juliet Erazo whose comments and suggestions greatly help to improve the quality of this manuscript. 


\section{REFERENCES}

Bessire, L. (2014). Behold the black caiman: A chronicle of Ayoreo life. United States: University of Chicago Press.

Beyette, B.J., \& LeCount, L.J. (Eds.). (2017). “The only true people”: Linking Maya identities past and present. United States: University Press of Colorado.

Blaser, M. (2014). Ontology and indigeneity: On the political ontology of heterogeneous assemblages. Cultural Geographies, 21(1), 49-58.

Bourdieu, P. (2013). Distinction: A social critique of the judgement of taste. United Kingdom: Routledge.

Castañeda, Q.E. (2004). "We are not indigenous!": An Introduction to the Maya Identity of Yucatán. The Journal of Latin American and Caribbean Anthropology, 9(1), 36-63.

Castillo Cocom, J.A., Rodríguez, T., \& Ashenbrener, M. (2017). Escaping Mayaland. In Beyette and LeCount (Eds.), The only true people (pp. 47-72). United States: University Press of Colorado.

Cepek, M. (2018). Life in Oil: Cofán Survival in the Petroleum Fields of Amazonia. United States: University of Texas Press.

Csordas, T.J. (1990). Embodiment as a Paradigm for Anthropology. Ethos, 18(1), 5-47.

De Certeau, M. (1997). Culture in the Plural. United States: University of Minnesota Press.

De La Cadena, M. (2015). Earth Beings: Ecologies of Practice across Andean Worlds. Durham, NC: Duke.

De La Cadena, M., \& Starn, O. (Eds.). (2007). Indigenous experience today (Vol. 2). United Kingdom: Berg Publishers.

Erazo, J., \& Jarrett, C. (2018). Managing alterity from within: The ontological turn in anthropology and indigenous efforts to shape shamanism. Journal of the Royal Anthropological Institute, 24(1), $145-163$.

Fabian, J. (2014). Time and the other: How anthropology makes its object. United States: Columbia University Press.

Fahim, H., \& Helmer, K. (1980). Indigenous anthropology in non-Western countries: A further elaboration. Current Anthropology, 21(5), 644-663.

Fanon, F. (2007). The wretched of the earth. United States: Grove/Atlantic, Inc.

Fassin, D. (2001). The biopolitics of otherness: Undocumented foreigners and racial discrimination in French public debate. Anthropology Today, 17(1), 3-7.

Foucault, M. (1990). The history of sexuality: An introduction. United States: Vintage.

Fuchs, S. (2001). Beyond agency. Sociological Theory, 19(1), 24-40.

Gabbert, W. (2004). Becoming Maya: Ethnicity and Social Inequality in Yucatán Since 1500. United States: University of Arizona Press.

Geertz, C. (1974). "From the Native's Point of View": On the Nature of Anthropological Understanding. Bulletin of the American Academy of Arts and Sciences, 28(1), 26-45. doi: 10.2307/3822971

Gregory, D. (2004). The Colonial Present: Afghanistan, Palestine, Iraq. Malden, MA: Blackwell Pub.

Gupta, A., \& Ferguson, J. (Eds.). (1997). Culture, power, place: Explorations in critical anthropology. United States: Duke University press.

Hale, C. (2004). Rethinking indigenous politics in the era of the "indio permitido". NACLA Report on the Americas, 38(2), 16-21.

Hale, C. (2006). Más que un indio: Racial ambivalence and the paradox of neoliberal multiculturalism in Guatemala. Santa Fé: School of American Research Press.

Hays, S. (1994). Structure and agency and the sticky problem of culture. Sociological Theory, pp. 57-72.

Hill, J.D. (Ed.). (1996). History, Power, and Identity: ethnogenesis in the Américas, 1492-1992. United States: University of Iowa Press.

Hipwell, W.T. (2007). Taiwan aboriginal ecotourism: Tanayiku natural ecology park. Annals of Tourism Research, 34(4), 876-897.

Hooker, J. (2005). Indigenous inclusion/black exclusion: Race, ethnicity and multicultural citizenship in Latin America. Journal of Latin American Studies, 37(2), 285-310. 
Hunt, S. (2014). Ontologies of Indigeneity: The politics of embodying a concept. Cultural Geographies, 21(1), 27-32.

Hutchins, F., \& Wilson, P.C. (Eds.). (2010). Editing Eden: A reconsideration of identity, politics, and place in Amazonia. United States: University of Nebraska Press.

Jackson, J.E. (2009). Neoliberal multiculturalism and indigenous movements. Latin American Research Review, 44(3), 200-211.

Kosko, S.J. (2013). Agency vulnerability, participation, and the self-determination of indigenous peoples. Journal of Global Ethics, 9(3), 293-310. DOI: 10.1080/17449626.2013.818385

LaRocque, E. (2011). When the other is me: Native resistance discourse, 1850-1990. Canada: University of Manitoba Press.

Macas, L., Belote, L., \& Belote, J. (2003). Indigenous Destiny in Indigenous Hands. Millennial Ecuador: Critical Essays on Cultural Transformations and Social Dynamics. Iowa City: University of Iowa Press. Retrieved May 29, 2019, from https://ehrafworldcultures-yaleedu.ezproxy.fiu.edu/document?id=sd17-004

Martinez Novo, C. (2006). Who defines indigenous?: Identities, development, intellectuals, and the state in northern Mexico. New Brunswick, NJ: Rutgers University Press.

Meyer, J.W., \& Jepperson, R.L. (2000). The 'actors' of modern society: The cultural construction of social agency. Sociological Theory, 18(1), 100-120.

Mitchell, T. (1991). Colonising Egypt: With a new preface. United States: University of California Press.

Montejo, V. (2002). The multiplicity of Mayan voices: Mayan leadership and the politics of selfrepresentation. Indigenous Movements, Self-Representation, and the State in Latin America, pp. $123-148$.

Nash, J.C., Conklin, B.A., Ayora-Diaz, S.I., Glaskin, K., Gleach, F.W., Field, L.W., . . Stoll, D. (2013). Anthropology and the Politics of Representation. United States: University of Alabama Press.

Niezen, R. (2000). Recognizing indigenism: Canadian unity and the international movement of indigenous peoples. Comparative Studies in Society and History, 42(1), 119-148.

Palmié, S. (2013). The cooking of history: How not to study Afro-Cuban religion. United States: University of Chicago Press.

Paradies, Y. (2016). Beyond black and white: Essentialism, hybridity and indigeneity. In Handbook of Indigenous Peoples' Rights (pp. 44-54). United Kingdom: Routledge.

Peirano, M.G. (1998). When anthropology is at home: The different contexts of a single discipline. Annual Review of Anthropology, 27(1), 105-128.

Postero, N.G. (2007). Now we are citizens: Indigenous politics in postmulticultural Bolivia. Stanford, CA: Stanford University Press.

Pred, A. (2004). The past is not dead. Minneapolis: University of Minnesota.

Rabinow, P. (1985). Discourse and power: On the limits of ethnographic texts. Dialectical Anthropology, 10(1), 1-13.

Rappaport, J. (2005). Intercultural utopias: Public intellectuals, cultural experimentation, and ethnic pluralism in Colombia. United States: Duke University Press.

Restall, M. (2004). Maya ethnogenesis. Journal of Latin American Anthropology, 9(1), 64-89.

Ribeiro, G.L. (2011). Why (post) colonialism and (de) coloniality are not enough: A post-imperialist perspective. Postcolonial Studies, 14(3), 285-297.

Robbins, P. (2012). Environmental Subjects and Identities. Political ecology: A critical introduction (Vol. 16). United Sates: John Wiley \& Sons.

Roosens, E.E. (1989). Creating ethnicity: The process of ethnogenesis. United States: Sage Publications, Inc.

Said, E.W. (1995). Orientalism: Western conceptions of the Orient. United States: Vintage Books.

Scott, J.C. (1990). Domination and the arts of resistance: Hidden transcripts. United States: Yale university press.

Sewell, W.H., Jr. (1992). A theory of structure: Duality, agency, and transformation. American Journal of Sociology, 98(1), 1-29.

118 Journal of Leadership Accountability and Ethics Vol. 18(6) 2021 
Shapiro, S.P. (2005). Agency theory. Annu. Rev. Sociol., 31, 263-284.

Smith, L.T. (2013). Decolonizing methodologies: Research and indigenous peoples. London: Zed Books Ltd.

Spivak, G.C. (1988). Can the subaltern speak? Can the subaltern speak? Reflections on the History of an Idea, pp. 21-78.

Spivak, G.C., \& Harasym, S. (2014). The post-colonial critic: Interviews, strategies, dialogues. United Kingdom: Routledge.

Thomas, N. (1994). Colonialism's culture: Anthropology, travel and government. United States: Princeton University Press.

Trouillot, M.R. (1995). Silencing the past: Power and the production of history. United States: Beacon Press.

Trouillot, M.R. (2003). Anthropology and the savage slot: The poetics and politics of otherness. In Global Transformations (pp. 7-28). New York: Palgrave Macmillan.

Tuck, E., \& Yang, K.W. (2012). Decolonization is not a metaphor. Decolonization: Indigeneity, Education \& Society, 1(1).

Vargas-Cetina, G. (2013). Introduction: Anthropology and the politics of representation. Anthropology and the Politics of Representation. United States: University of Alabama Press.

Warren, K.B., \& Jackson, J.E. (2003). Indigenous movements, self-representation, and the state in Latin America. United States: University of Texas Press.

Wilson, P., \& Stewart, M. (2008). Indigeneity and indigenous media on the global stage. Global Indigenous Media, pp. 1-35. 